\title{
The Empirical Study on Market Liquidity and Determinants of Sukuk in Malaysia
}

\author{
Norshafizah Hanafi ${ }^{\star}$, Amirul Hamiza Abdul Hamid, Jasmani Mohd Yunus \\ UUM Kuala Lumpur, Universiti Utara Malaysia
}

\begin{abstract}
The purpose of this study is to examine the relationship between market liquidity and the determinants of Sukuk from Malaysia's perspective. This study also determines whether the Sukuk market is reacting as similar to the bond market regarding market liquidity. A sample of 933 issued Sukuk in Malaysia is collected from secondary data of Bond Pricing of Agency Malaysia (BPAM) and Bond Info hub of Bank Negara Malaysia from the period of 2005 to 2015. The sample of issued Sukuk is based on Malaysian Ringgit denominated currency and these Sukuk are actively traded in the secondary market of Malaysia. The sample comprises five (5) sectors inclusive government, quasi-government, finance, asset-backed securities (ABS) and corporates. Market microstructure theory is using on the impact of numerous market frictions in the market structure and individual behaviour during the price determination process in this study. The empirical results of this study show that age and maturity have a positive relationship with Sukuk market liquidity and they are significantly correlated. The findings of this study could assist investors in the making decision by choosing the right type of Sukuk structure and by utilising the suitable Sukuk determinants at the right time. From the analysis, the researcher concludes that investors prefer to hold their securities until meeting its maturity rather than traded it in the secondary market. Further research should be done by incorporating other liquidity factors such as the liquidity risk, yield spread and price in order to have more input to the study on liquidity since the Sukuk market is increasing in demand and becomes more sophisticated as the financial market is moving towards digitalisation and electrification.
\end{abstract}

Keywords: Sukuk, Market liquidity, Malaysian Islamic capital market, Maturity, Coupon rate, Credit rating

JEL Classification: G30

Paper Type: Research

* Corresponding author: E-mail: norshafizah@uum.edu.my 
The Empirical Study on Market Liquidity and Determinants of Sukuk in Malaysia

\section{INTRODUCTION}

The purpose of this study is to examine the relationship between market liquidity and the determinants of Sukuk in Malaysia's perspective. Sukuk as an innovator of Islamic capital market's product is becoming increasingly popular and influential. The unique feature of Sukuk is designed to comply with Shariah principles. The most common structure is that investors receive dividends instead of interest from the sale and buyback transaction. In essence of having more market players to participate in the market, Duffe et al. (2005) dictate that a higher turnover agent will enhance liquidity due to the transaction cost involved is lower. Thus, it is interesting to know whether market liquidity against Sukuk determinants will have a similar result as the bonds or not. This is because Sukuk is not based on debt capital, but it is free from the forbidden interest or the riba. There is a variety of liquidity measurements proposed by prior studies. However, for this research, only two liquidity measures are being focused which are the bid-ask spreads and the Amihud (2002) measure.

This paper seeks to examine the relationship between market liquidity and the determinants of Sukuk in Malaysia. It should be noted that investigations of the previous literature on these relationships are very limited. There are numerous studies on market liquidity which mainly focus on the bond market, however only a few studies in the Sukuk market, despite Sukuk's characteristic that is free from speculation. Hence, this paper explores the determinants of Sukuk and the market liquidity through secondary data collected from the Bond Pricing Agency Malaysia (BPAM) database and Bond Info Hub of Bank Negara Malaysia

By utilising the previous literature relating to market liquidity, the objective of this paper is to investigate the relationship between market liquidity and determinants of Sukuk in the perspective of Malaysia. Since Sukuk is not a loan based on debt capital as the conventional bond, it is interesting to know how market liquidity reacts to Sukuk determinants. It is hoped this study may benefit the investors during the decision making whether to invest in Sukuk market or conventional market and also the policymakers for the improvement in the Sukuk market. There are six variables of Sukuk proxies for this study, which are the maturity, coupon rate, age, credit rating, number of trading and amount of trading.

It is the aim of this study to meet the research objective by determining the relationship between market liquidity and determinants of Sukuk in the perspective of Malaysia through the research question: Is there any relationship between the determinants of Sukuk (represented by maturity, coupon rate, age, credit rating, number of trades and amount of trading) and market liquidity?

Based on the research question, this study is undertaken to provide a better understanding of the Sukuk determinants and market liquidity in the following aspect. Thus, the objective of this paper is to examine the relationship between market liquidity and the determinants of Sukuk, which are proxied by the maturity, coupon rate, age, credit rating, number of trades and amount of trading sukuk.

The study is significant as it could assist investors in the making decision by choosing the right type of Sukuk structure and by utilising the suitable Sukuk determinants at the right time. Similarly, this study allows the policymakers to revise on existing policies of the secondary market in the Malaysian Sukuk market. Hence, it paves the way to improving the Malaysian Sukuk market specifically in the secondary market. Furthermore, the study enriches the literature on Islamic capital market relating to market liquidity in Malaysia. These all depend on the suitability and intensity of the investors' interest. 


\section{LITERATURE REVIEW}

This study involves with variables inclusive the market liquidity, maturity, age, coupon rate, credit ratings, number of trades and amount of trading Sukuk in the secondary market where they can be categorised into independent variables and dependent variable. The following subsections explain further on these variables.

\subsection{Dependent Variable}

Market liquidity is a major concern for investors, practitioners and policymakers, especially during a financial crisis. Therefore, it is crucial to maintaining adequate levels of liquidity because liquidity smoothens the functioning of financial markets (Datar, Naik and Radcliffe, 1998). The higher ability to convert the investment asset into cash would give a better preferential to attract more investors. The dependent variable is what is being measured in an experiment that is changed by the effect of independent variables.

Liquidity can be defined as the ability an asset of investment to be converted into cash within reasonable of the period at a reasonable price. In other words, the market can execute a large number of trades without causing excessive price movements (IOSCO, 2007). Liquidity is a multi-dimensional concept that refers to the ability to perform large transactions without much price effect in which it can be associated with low transaction costs and immediacy in execution. Alternatively, market liquidity is the ability to carry out large securities transactions at a low cost without much price impact (Brandao-Marques et al., 2015). Meanwhile, liquidity in the corporate bond market can be defined as the bond's ability to be traded in large trades at low-cost asset without a significant impact on its price (Jack, 2016).

Based on the drivers of market liquidity levels and resilience, namely: (1) the risk appetite constraints in funding and market risks faced by financial intermediaries, (2) the search costs that influence the speed of matching the buyers and sellers, and (3) investor's characteristics and behavior that reflect different mandates, constraints, and access to information (Vayanos \& Wang, 2012; Duffie, 2012). For instance, investors who are riskseekers tend to invest in securities with a higher risk with the perception to receive for better returns. Thus, this led the market to become more liquid and better resiliency.

\subsection{Independent Variable}

The independent values are variables that influence the dependent variable in either a positive or negative relationship. Independent variables are related to each other in the presence of dependent variable and independent variable. In this study, the determinants of Sukuk are the independent values include the maturity of the Sukuk, age, coupon rate, credit ratings, number of trades and volume of trading. The issuer will determine the size of the issuance, age of sukuk, coupon rate and maturity of Sukuk but not the market.

\subsubsection{Maturity}

According to a study by Mahanti, Nashikkar, Subrahmanyam, Chacko and Mallik (2008) relating to bond maturity, it appears that bonds with lower original maturity that is five and seven years have greater liquidity than bonds with higher maturity of ten years or 30 years. Hence, for long-term buy-and-hold investors such as insurance companies, they have long-dated liabilities. In other words, for investors who hold bonds with longer maturity, they tend to hold them in which makes the bond market to be less liquidity. This theoretical 
price error (OPE) depends on the time to maturity. The longer is the maturity, the higher will be the OPE.

\subsubsection{Age}

The age factor is also one of the liquidity determinants. Studies by Sariq and Warga (1989); and Alexander, Edwards and Ferri (2000) conclude that there is a relationship between age of bond and liquidity. In their studies, it has shown that corporate bonds which newly issued were more actively traded rather than the older bonds. A study by Leung (2014) finds that the new sukuk issuances are more liquid than the older ones. Moreover, as the size of Sukuk issuance is increased, the more liquidity the Sukuk would be. Meanwhile, bond with current age is found to have an adversely strong relationship with liquidity (Mahanti et al., 2008). That is, as the age of the bonds increase, market liquidity would then be reduced.

\subsubsection{Coupon rate}

Based on a study by Jovanovic and Rousseau (2001) relating to the impact of liquidity in the bond market discover that liquidity has a significant influence on the interest rates caused by the supply of bonds but not on the supply of money. In contrast, Mahanti et al. (2008), Friewald et al. (2012) and Rusmawati et al. (2013) verify that the coupon rate was found to have a negative relationship with liquidity. The higher the rate, the lower the market liquidity would be.

\subsubsection{Credit rating}

The commencement of Islamic bond rating in early 1994 has embarked another milestone in the Islamic bond market. The purpose of bond ratings is to judge the credit risk and undertake ratings of corporate debt issues (Mohd Asri et al., 2004). As of today, Malaysia has two rating agencies namely the Rating Agency Malaysia Berhad (RAM) and Malaysia Rating Corporation Berhad (MARC). Both of these rating agencies play an essential role in the development of the Malaysian market for conventional and Islamic Private Debt Securities (IPDS). Rating Agency Malaysia (RAM) has come out with rating definition based on debt-based Sukuk.

\subsubsection{Numbers of trade}

According to Chordia, Roll and Subrahmanyam (2001) that when the market volatility is increased, the spread is concurrent will be reduced. Furthermore, Alexander, Edwards and Ferri (2000) agree with the original finding of Demsetz (1968) that the more active markets, the more liquid it will be. When the stocks being traded frequently, it reduces the bid-ask spreads or lower transaction costs. As the transaction costs are lower, the cheaper the provision of liquidity services, which lead to higher profits for dealers.

\subsubsection{Volume of trading}

A study by Chordia et al. (2000) finds that there is a positive relationship between liquidity and trading volume, whereas a negative relation between quoted spread and liquidity. The larger the trading volume, the more liquid the market would be but the greater the differences in the quoted spread, the lower will the liquidity. Schultz (2001) finds that bidask spreads or transaction costs decline with trading size and a customer's trading activity. 
Here, Schultz used a large sample of corporate bond transactions of US insurance companies to derive such a conclusion.

\section{THEORETICAL FRAMEWORK}

This paper aims to investigate the relationship between market liquidity and Sukuk's determinants. The relationship between the dependent variable and independent variables are depicted in the theoretical framework as described in Figure 1.

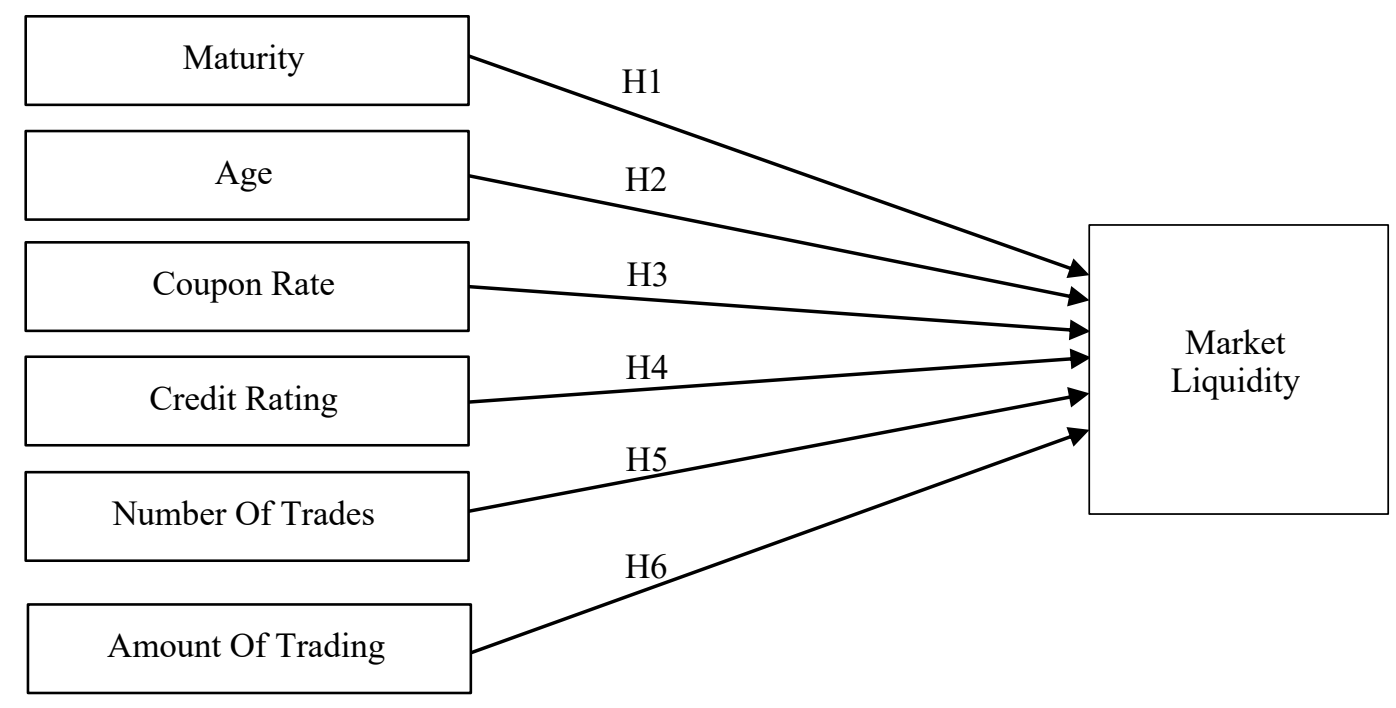

Figure 1. The theoretical framework of the study

The hypotheses of this study are as follow:

$\mathrm{H}_{1}$ : There is a significant relationship between the maturity of Sukuk and market liquidity. Bao et al. (2008) in their study to investigate the relationship between the liquidity of corporate bonds with the impact of asset-pricing have found that bonds with higher maturity are more liquid than with lower maturity.

$\mathrm{H}_{2}$ : There is a significant relationship between age of Sukuk and market liquidity. Alexander et al. (2000) and Leung (2014) reveal that the relationship between age of corporate bonds and liquidity is related significantly.

$\mathrm{H}_{3}$ : There is a significant relationship between the coupon rate of Sukuk and market liquidity. Studies were undertaken by Mahanti et al. (2008), Friewald et al. (2012) and Rusmawati et al. (2013) reveal that the coupon rate has a significant negative relationship with liquidity. They have proved that coupon rate was the significant determinant for liquidity.

$\mathrm{H}_{4}$ : There is a significant relationship between credit rating and market liquidity.

According to Fridson and Garman (1998) that the credit rating of bonds are found significantly correlated with bond liquidity.

$\mathrm{H}_{5}$ : There is a significant relationship between some trades and market liquidity.

There are few studies undertaken by Chordia et al. (2001) and Demsetz (1968) that discover the significant relationship between some trades and market liquidity. A number 
of trades are influenced by transaction costs. When transaction costs in the dealer market are reduced, more market participants will enter into the market. As a result, the market becomes more active and more volatility due to the increased transactions. However, when the transactions costs are high, it would reduce the number of market participants. Consequently, the market liquidity would also decrease.

$\mathrm{H}_{6}$ : There is a significant relationship between the amount of trading and market liquidity. Alexander et al. (2000) and Chordia et al. (2000) have discovered that the higher the amount of trading being traded in the market, the higher would be the liquidity. Hence, the relationship between the amount of trading and market liquidity is significantly related.

\section{RESEARCH METHODS}

\subsection{Data Collection and Sample Selection}

The data are collected from the Bond Pricing Agency Malaysia (BPAM) database and Bond Info Hub of Bank Negara Malaysia (www.bondinfo.bnm.gov.my). The sample size in this study consists of 933 of Sukuk issued in Malaysia, which represents a full sample for eleven consecutive years' period from 2005 to 2015 . This sample size is determined by the availability of data in which only issued Sukuk under active status and sufficient data are being studied. In other words, Sukuk that have been redeemed, suspended, still on pending and data is available shall be excluded from this study.

The data issued Sukuk from the database of Bond Pricing Agency Malaysia is classified under five (5) sectors which are the Government, Quasi-government, Finance; Asset-Backed Securities (ABS) and Corporates. The initial total of active issued Sukuk in the primary market is 8,656 records. Each record represents for the Sukuk issued in Malaysia denominated in Malaysian Ringgit (MYR). The details of the distribution of issued Sukuk are illustrated in Table 1.

Table 1. The distribution of issued Sukuk according to Sector (from 2005 - 2015)

\begin{tabular}{|c|c|c|c|c|c|}
\hline \multirow{3}{*}{ Sector } & \multicolumn{4}{|c|}{ Issued Sukuk traded in the secondary market } & \multirow{3}{*}{$\begin{array}{c}\text { Total issued } \\
\text { at primary } \\
\text { market }\end{array}$} \\
\hline & \multicolumn{2}{|c|}{ Active } & \multirow{2}{*}{ Redeemed } & \multirow{2}{*}{$\begin{array}{l}\text { Suspended/ } \\
\text { Pending }\end{array}$} & \\
\hline & Complete & Insufficient Data & & & \\
\hline Finance & 37 & 3 & 18 & 0 & 64 \\
\hline Government & 47 & 0 & 232 & 0 & 277 \\
\hline Quasi-Government & 145 & 34 & 168 & 0 & 388 \\
\hline Corporate & 698 & 96 & 5,516 & 60 & 6762 \\
\hline $\begin{array}{l}\text { Asset Backed } \\
\text { Securities (ABS) }\end{array}$ & 6 & 2 & 51 & 0 & 70 \\
\hline BNM & $\begin{array}{c}\text { Not } \\
\text { available }\end{array}$ & - & 1,095 & - & 1095 \\
\hline Sub-total & 933 & 135 & 7,080 & 60 & 8,656 \\
\hline
\end{tabular}

Source: Bond Pricing Agency Malaysia Database

Those records of 8,656 derived from the primary market are then matched with available records in the secondary market according to the stock code. Finally, after matching and sorting, only 933 records remain which represents $10.78 \%$ from total records issued during the study period. All of these 933 records are a long-term type of Sukuk. Hence, no shortterm Sukuk being investigated.

The sample size determination as proposed by Krejcie and Morgan (1970) for a population of 9,000 is 368 representing $4.09 \%$. For this study, the sample size is 933 or $10.78 \%$ out of the total population. Therefore, the sample size that represents $10.78 \%$ of 
the population of Sukuk from the year 2005 to 2015 is acceptable because it is still within the tolerable range.

\subsection{Measurement of Variables and Instrument}

The researcher employs IBM Statistical Package of Social Science (SPSS) version 24.0 as a tool to perform the data analysis. Several statistical techniques are being used in this study in generating a statistical report, which are the descriptive statistics, correlations analysis and regressions analysis. This section also highlights the measurement of the dependent variable and independent variables as being studied. The dependent variable is market liquidity. The market is said to be liquid when agents can buy or sell without having much impact on the price. There are three features of market liquidity based on Kyle (1985) which are tightness, depth, and resilience. Tightness is measured as the bidask spread that results from the difference between actual price and trade price. The depth shows the volume of the security to be traded at the current market price. Meanwhile, resilience is associated with the convergence speed from the price level caused by the price changes at random.

The study adopted two measurements as a proxy to liquidity. The measurements are a) bid-ask spreads and b) Amihud (2002) measure. The bid-ask spread is known as the best measure of liquidity (Bouchaddekh \& Bouri, 2013). The bid ask-spread is used to determine the liquidity of an investment. According to Sarr and Lybek (2002), the bid-ask spread is associated to almost of transaction costs (i.e. order processing costs, taxes, execution costs), in which is referred as transaction costs measure. The higher transaction costs, the higher would be the bid-ask spreads, which led to a reduction in the volume of trading as caused by a reduction in potential active market participants. As a result, lower its liquidity.

The bid-ask spread is measured by deducting the lowest ask price that a seller is willing to sell from the highest bid price that a buyer is willing to buy. In short, it is the absolute value from the difference between the highest bid prices and the lowest ask prices in the market. The bid-ask spread can be measured either as the difference between the bid and ask prices (equations 1a) or as a percentage spread shown in equation $1 \mathrm{~b}$ as illustrated:

Spread $=\left(P_{a}-P_{b}\right)$; where $P_{a}$ is the asking price and $P_{b}$ is the bid price (equation 1a) Spread $=\left(P_{a}-P_{b}\right) /\left(\left(P_{a}+P_{b}\right) / 2\right)$

The Amihud (2002) measure, it is a popular measure that was initially proposed by Yakov Amihud who is a Finance Professor from New York University. His works mainly focus on the liquidity of stocks and bonds and also the methods and systems of trading market securities. The Amihud (2002) measure was initially proposed by Kyle (1985). This measurement calculates the price impact (i.e. price change) measured in returns, over the trade volume measured in US dollar (Friewald et al., 2012). The calculation for this measure is illustrated as per the formulae:

$$
\operatorname{Amihud}_{t}=\frac{1}{N_{t}} \sum_{j=1}^{N_{t}} \frac{\left|r_{j}\right|}{V_{j}}
$$

This Amihud (2002) measures at day $t$ for a specific bond over a particular period that involved with some observed returns depicted as $N_{t}$. It is calculated based on the average 
ratio between the absolute value of the returns referred as $r_{j}$ and its trading volume; namely $v_{j}$.

In this study, the measurement for independent variables is quite straightforward because all the variables are directly taken from the database provided by Bond Pricing Agency Malaysia (BPAM) except for maturity. For variables coupon rate, age and credit rating are obtained from the primary market in the data set of BPAM. As for the other two variables (i.e. the number of trades and amount of trading), they are retrieved directly from the secondary market of the BPAM database. Regarding the credit rating, the classification of each group is by Rating Agency Malaysia (RAM).

Regarding the credit rating, the classification of each group is by Rating Agency Malaysia (RAM). For example, " 1 " is assigned to group AAA rating; "2" is assigned to group AA1 to AA3; " 3 " is assigned to group rating of A1 to A3; " 4 " is assigned to group BBB1 to BBB3 and so forth. The definition of each credit rating can be found in Appendix A. The variable of maturity as defined by Ross et al. (2010) as the remaining number of years until the bond's face value is paid. Once a bond is issued, the number of years to maturity drops as time goes by. Therefore, the maturity in this study is calculated using the below equation:

$$
\text { Maturity }=\frac{\text { Maturity Date }- \text { Current Date }}{365 \text { days }}
$$

where the current date in this study is taken as at 01/01/2016

The focus of this study is to investigate the relationship between dependent and independent variables by adopting a few measurements as explained in the following subsection.

\subsubsection{Descriptive Statistics}

Descriptive statistics are a brief descriptive on coefficients that summarise a given data set. It is also used to interpret the basic measures such as the minimum, maximum, mean and standard deviation. Moreover, the descriptive statistics technique can also be used to measure the spread of the observed data from the value range.

\subsubsection{Correlation}

Correlation describes the relationship between two or more variables either positive or negative. The closer the correlation coefficient is to 1.0, the stronger the relationship will be. In contrast, when the correlation is 0 , it denotes the absence of a relationship.

Correlation with the positive sign indicates that the variables are moving in the same direction and vice versa. Meanwhile, the Sig.2 tailed indicates the level of confidence in the relationship. In SPSS version 24, there is two (2) types correlation that is Pearson Product Moment Correlation Coefficient ( $r$ ) and Spearman Rank Order Correlation (rho). However, Spearman correlation is best used for the non-parametric statistics (Pallant, 2016). In this study, it also calculates the coefficient of determination by square the $r$ value. This value shows the variance between the two variables.

\subsubsection{Multiple Regression Analysis}

Multi regression analysis is a type of statistical analysis which is used to identify the strength of the relationship between one continuous dependent variable and either one or 
more of independent variables. It is based on the correlation in which regression provides an understanding of how well the value of the dependent variable changes when one of the independent variables is changed, while remains the other independent variables. The relationship is expressed in a mathematical equation, and it provides results of the dependent variable based on the values of independent variables.

The regression model that includes all the variables is reproduced:

$$
\begin{aligned}
& Y=\alpha+\beta_{1} X_{1}+\beta_{2} X_{2}+\beta_{3} X_{3}+\beta_{4} X_{4}+\beta_{5} X_{5}+\beta_{6} X_{6}+X_{i t} \\
& \text { Where, } \\
& \alpha \quad=\text { Constant } \\
& \mathrm{Y}=\text { Dependent variable which represents market liquidity } \\
& \beta_{1}, \beta_{2}, \beta_{3}, \beta_{4}, \beta_{5}, \beta_{6}=\text { Coefficient to be estimated based on the slopes of the relationship } \\
& \mathrm{X}_{1} \quad=\text { Independent variable which represents maturity } \\
& \mathrm{X}_{2} \quad=\text { Independent variable which represents the age } \\
& \mathrm{X}_{3} \quad=\text { Independent variable which represents coupon rate } \\
& \mathrm{X}_{4} \quad=\text { Independent variable which represents credit rating } \\
& \mathrm{X}_{5} \quad=\text { Independent variable which represents the number of trades } \\
& \mathrm{X}_{6} \quad=\text { Independent variable which represents the amount of trading } \\
& \mathrm{X}_{\mathrm{it}} \quad=\text { Term of random error which is part of the dependent variable }
\end{aligned}
$$

\subsubsection{Analysis of Variance (ANOVA)}

Briefly, the analysis of variance or known as ANOVA is the most frequent analysis used in the study of behavioural sciences (Howell, 1999). It allows the mean scores of more than two groups to be compared concurrently. In other words, ANOVA compares the variance between the independent variables that if the result shows $p$-value less than or equal to 0.05 (shows as Sig.), then the statistical is significant.

\section{FINDING}

From the 933 Sukuk records listed in the dataset of Bond Pricing Agency Malaysia (BPAM) from 2005 to 2015, the descriptive statistics show two dependent variables used as the proxies for market liquidity; Bid-ask Spread (basis points) and Amihud (2002) measure together with independent variables as shown in Table 2.

Table 2. Independent variable and measurement

\begin{tabular}{|c|l|l|}
\hline No. & Independent Variable & Measurement \\
\hline 1 & Maturity of Sukuk & In years \\
\hline 2 & Age or tenor of the issued Sukuk & In years \\
\hline 3 & The coupon rate of Sukuk & In percentage \\
\hline 4 & Credit rating & Associates with a class number from 1 to 9 \\
\hline 5 & $\begin{array}{l}\text { Amount of traded. Traded volume is the size of the } \\
\text { issued Sukuk. }\end{array}$ & In Millions \\
\hline 6 & Log of Number of trade & In number \\
\hline
\end{tabular}

Some trading for each issued Sukuk being traded in the secondary market. Because the value of traded volume and number of trades involves large value, the natural log is taken for a more meaningful value. 
Table 3. Correlation and regression results

\begin{tabular}{|c|l|c|c|}
\hline No. & Independent Variable & Correlation & Regression \\
\hline 1 & Maturity of Sukuk & Positive & Significant \\
\hline 2 & Age or tenor of the issued Sukuk & Positive & Significant \\
\hline 3 & The coupon rate of Sukuk & Positive & Not significant \\
\hline 4 & Credit rating & Positive & Not significant \\
\hline 5 & $\begin{array}{l}\text { Amount of traded. Traded volume is the size of the } \\
\text { issued Sukuk. }\end{array}$ & Negative & Not significant \\
\hline 6 & Log of Number of trade & Negative & Not significant \\
\hline
\end{tabular}

Age has a positive relationship with liquidity either using bid-ask spread or Amihud (2002) measure even though the relationships are quite weak. This reveals that the longer the Sukuk are held till maturity, the more active it is traded in the secondary market. The results of maturity variable from both measures, it has shown that maturity is positively correlated with market liquidity which is significantly correlated, but the relationship's strength is considered as weak. It means, for Malaysian investors, they tend to hold Sukuk with a shorter maturity. The shorter maturity the investors hold, the lesser would be the market liquidity (Mahanti et al., 2008). As for the coupon rate, the relationship exists between coupon rate and market liquidity is positive but it is not significant. Given descriptive statistics, coupon rate has an average of 5.32 per cent, whereby the minimum rate is at 2.5 per cent, and the maximum is at 100.1 per cent. Thus, it appears that there is a tendency for investors to buy Sukuk with a lower coupon rate since the lower interest rate is associated for lower risk.

Regarding credit rating, there two different results derive from different measures. Firstly, when the bid-ask spread measure is used, credit rating variable is found to have a positive relationship with liquidity except it does not significantly correlated to Sukuk 's liquidity. Secondly, when Amihud (2002) measure is used, credit rating is negatively correlated with liquidity. This is consistent with Rusmawati et al. (2013) that conclude Sukuk's credit rating is negatively related to market liquidity.

\section{CONCLUSION}

Age and maturity have a positive relationship with Sukuk's liquidity, but it does not significantly prove that the Sukuk market in Malaysia is liquid. It is the culture for investors to hold the securities until maturity rather than traded it in the secondary market. As remarked by Zaidi (2007) as the CEO of Islamic International Rating Agency of Bahrain that investors with buying and hold culture rather than trading the securities in the secondary market have led to inefficiency in the market (Zaidi, 2007). Therefore, from the above findings, it can be concluded that the Sukuk market in Malaysia is a very illiquid market. This proves that the Sukuk market in Malaysia is not significantly liquid. Even though Malaysian Sukuk is the world largest issuance, it does not mean that the securities are also actively traded in the secondary market of Malaysia.

Several factors interfere with the smooth operation of the Sukuk market in Malaysia such as the global economic crisis, behavioural of market participants and resiliency of financial institutions. Due to the globally increasing demand for Islamic capital market products such as Sukuk, the study on products that are Shari'ah compliant is a necessity to overcome any hiccups in the management of Islamic capital market for a smooth and resilience financial system. This study is hoped to be the pioneer in the investigations in Sukuk's market liquidity. Further research should be done by incorporating other liquidity factors such as the liquidity risk, yield spread and price in order to have more input to the study on liquidity since the Sukuk market is increasing in demand and becomes more sophisticated as the financial market is moving towards digitalisation and electrification. 


\subsection{Scope and Limitations of the Study}

There are also worth to note that the scope of this research is limited to empirical research using secondary data from the Bond Pricing Agency Malaysia (BPAM) and Bond Info Hub of Bank Negara Malaysia. The research data covers such as coupon rate, maturity, age, credit ratings, amount of sukuk outstanding, number of Sukuk trades and the trading amount in the Malaysian Sukuk market from 2005 to 2015.

There are also some limitations in this study which include:

a) The availability of data from Bond Pricing Agency Malaysia is limited up to five sectors inclusive Government, Quasi-government, Finance; Asset-Backed Securities (ABS) and Corporates. The Bank Negara Malaysia (BNM) sector is omitted due to the absence of ample data.

b) This study is only based on Sukuk that are remained inactive. In other words, sukuk that have been redeemed suspended and still on pending shall be excluded from this study.

c) This study is limited due to the absence of sufficient data to be carried for this study as there are only 933 records of Sukuk data which represents $10.78 \%$ from the total of 8,656 records in the Sukuk market in Malaysia. These 933 records represent $87.36 \%$ of the total of 1,068 existing sukuk in the database of Bond Pricing Agency Malaysia (BPAM).

d) Based on the secondary data from Bond Pricing Agency Malaysia database, the amount issuance is captured neither in the primary market nor secondary market. Due to the absence of data on the amount of issuance, hence investigation that involves the amount of issuance could not be taken and will be ignored.

\section{REFERENCES}

Alexander, G. J., Edwards, A. K., \& Ferri, M. G. (2000). The Determinants of Trading Volume of High-Yield Corporate Bonds, Journal of Financial Markets, 3(2) 177-204.

Amihud, Y. (2002). Illiquidity and stock returns: cross-section and time-series effects, Journal of Financial Markets, 5(1), 31-56.

Bank Negara Malaysia. (1999). The Central Bank and the Financial System in Malaysia - A Decade of Change. Kuala Lumpur: Bank Negara Malaysia.

Bao, J., Pan, J. \& Wang, J. (2008). Liquidity of Corporate Bonds. Available at SSRN: https://ssrn.com/abstract=1106852 or http://dx.doi.org/10.2139/ssrn.1106852/

Brandao-Marques, L., Gonzalez-Hermosillo, B., Bouveret, A., Han, F., Jones, D., Kiff, J., Lambert, F., Monroe, W., Khadarina, O., Valderrama, L., \& Yan, K., (2015). International Monetary Fund. Retrieved from http://www.imf.org/External/Pubs/FT/GFSR/2015/02/pdf/cr_v2.pdf

Bouchaddekh, T. \& Bouri, A. (2013). Measures, Determinants and Commonality in Liquidity: Empirical Tests on Tunisian Stock Market. International Journal of Science and Research, 4(1), 347-355.

Chordia, T., Richard W., Roll, R. \& Subrahmanyam, A. (2000). Commonality in liquidity, Journal of Financial Economics, 56(1), 3-28.

Chordia, T., Roll, R., \& Subrahmanyam, A.(2001). Market liquidity and trading activity. Journal of Finance, 56(2), 501-530.

Datar, V.T., Naik, N., \& Radcliffe, R.(1998). Liquidity and stock return: An alternative test. Journal of Financial Markets, 1(2), 203-219.

Demsetz, H. (1968). The Cost of Transacting. The Quarterly Journal of Economics, 82(1), 33-53.

Duffie, D., Garleanu, N., \& Pedersen, L.H. (2005). Over the Counter Markets. Econometrica, 73(6), 1815- 1847. doi: http://dx.doi.org/10.1111/j.1468-0262.2005.00639.

Duffie, D. (2012). Market Making under the Proposed Volcker Rule. Working Paper 106, Rock Center for Corporate Governance at Stanford University, Palo Alto, California. 
Fridson, M. S. \& Garman, M. C. (1998). Determinants of Spreads on New High-Yield Bonds, Financial Analysts Journal, 54(2), 28-39.

Friewald, N., Jankowitsch, R., \& Subrahmanyam M.G. (2012). Illiquidity or credit deterioration: A study on liquidity in the US corporate bond market during financial crises. Journal of Financial Economics. 105, 18-36.

Jack, D. (2016). Why Liquidity Matters in the Corporate Bond Market. Retrieved from https://www.investopedia.com/articles/investing/012216/why-liquidity-matters-in-thecorporate-bonds-market.asp

Jovanovic, B., \& Rousseau, P.L. (2001). Liquidity Effect in the Bond Market. National Bureau of Economic Research Working Paper No. 8957, (Nov), JEL No. E44, E5.

Kyle, A. S. (1985). Continuous auctions and insider trading. Journal of the Econometric Society, $1315-1335$

Leung, M. (2014). Sukuk Liquidity Trends. Sukuk 201 Global.

Mahanti, S., Nashikkar, A., Subrahmanyam, M., Chacko, G., \& Mallik, G. (2008). Latent liquidity:A new measure of liquidity, with an Application to Corporate Bonds, Journal of Financial Economics, 88(2) 272-298.

Mod Asri, N., Abdul Karim, Z., Shahimi, S. \& Al-Hadi, A. A. (2004). The effect of Islamic private debt securities rating changes on the firm's common stock returns. The Journal of Muamalat and Islamic Finance Research, 1(1), 25-38.

Ross, S. A., Westerfield, R. W., \& Jaffe, J. (2010). Corporate Finance. (9 $9^{\text {th }}$ ed.). New York: McGraw Hill.

Rusmawati, S., Wan Nurhanan, W, S., \& Asmaddy, H. (2013). Determinants of Islamic Bond (Sukuk): Evidence in Malaysia.

Sarig, O., \& Warga, A. (1989). Bond price data and bond market liquidity, Journal of Financial and Quantitative Analysis, 24(3) 367-378.

Sarr, A. \& Lybek, T. (2002). Measuring Liquidity in Financial Markets. IMF Working Paper. Retrieved from https://www.imf.org/external/pubs/ft/wp/2002/wp02232.pdf.

Schultz, P. (2001). Corporate bond trading costs: a peek behind the curtain. Journal of Finance, 56(2), $677-698$.

Vayanos, D., \& Wang, J. (2012). Market Liquidity: Theory and Evidence. NBER Working Paper 1825, National Bureau of Economic Research, Cambridge, Massachusetts.

Zaidi, J. A. (2007). Overcoming barriers to liquidity: Commoditization, Sukuk, promoting issuance and a secondary market. Islamic Finance and Investment World Europe. 